\title{
ON THE ACCUMULATION OF DYE IN NITELLA.
}

BY MARIAN IRWIN.*

(From the Laboratory of Plant Physiology, Harvard University, Cambridge.)

(Received for publication, June 21, 1925.)

I.

INTRODUCTION.

The large multinucleate cells of Nitella (about four inches in length) afford good opportunities for the study of permeability, and have therefore been used in the experiments described in this paper. The cell consists of a cell wall of cellulose, inside which is a thin layer of protoplasm surrounding a large central vacuole filled with sap which has a streaming movement.

Analysis $^{1}$ of the sap has shown that the cell has the power to store up halides to a remarkable degree so that they reach a concentration of a little over $0.1 \mathrm{M}$, while only a trace is present in the water in which the cell lives. The halides in the sap do not seem to come out of the vacuole unless the cells are injured or plasmolyzed. Not only the halides but many other substances are stored up in this manner.2 The writer has found that the young cells (one-half an inch in length) have the same concentration of halides as older cells (about six inches in length).

What is the explanation of the mechanism of storage? Is the determining factor physical or chemical? Does it lie in the cell wall, in the protoplasmic layer, or in the cell sap?

The only way to answer these questions is to analyze the process step by step. To do this it is necessary to use a substance which readily accumulates in the cell sap to a considerable extent without producing injury. Since only small quantities of sap are available, the substance chosen must be capable of easy and accurate measurement

* Fellow of the National Research Council, Washington, D. C.

${ }^{1}$ Irwin, M., J.Gen. Physiol., 1922-23, v, 427.

${ }^{2}$ Hoagland, D. R., and Davis, A. R., J. Gen. Physiol., 1922-23, v, 629.

147 
under these conditions. All of these requisites are quite satisfactorily met by the basic dye, brilliant cresyl blue.

II.

Methods.

For these experiments a Nitella collected in Cambridge was employed. On the average the sap contains $0.106 \mathrm{M}$ halides and the $\mathrm{pH}$ value of the sap is about 5.6.

Unless otherwise stated all experiments were made upon living cells in normal condition. In order to avoid experimental errors the cells were carefully selected for uniformity. Cells about four inches long, and similar as to thickness of cell wall, were taken from the central portion of the plant. ${ }^{3}$ Care was taken to select cells free from substances attached to the surface. Portions consisting of about three cells each were cut off and placed in tap water for a day in order to make certain that the cutting brought about no injury to the cells that were to be used.

Such strings of cells were placed for half an hour in buffer solutions having the same $\mathrm{pH}$ value, molecular concentration, and temperature, as the buffer solutions containing the dye.

The cells were then placed in a solution of dye and at intervals a few cells were removed from the solution. Each cell thus removed was rinsed, wiped dry, and cut at one end: the sap was then gently squeezed out on a glass slide and drawn up into a capillary tube which was matched colorimetrically with a capillary tube of the same diameter, containing the standard dye solution.

The dye used was brilliant cresyl blue. ${ }^{4}$ The molecular structure ${ }^{5}$ of the dye is not well determined, but it is approximately

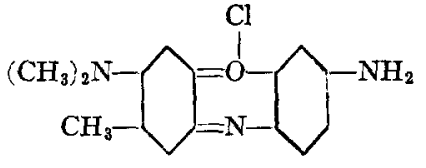

\footnotetext{
${ }^{3}$ The cells toward the base differ from those near the tip in the rate of accumulation of the dye.

${ }^{4}$ The dye used was made by the National Aniline Chemical Company or by Grübler. Since the rate of the accumulation of the dye made by Grübler is greater than in the case of that made by the National Aniline Chemical Company, the kind used will be stated in each case.

${ }^{5}$ Schultz, G., Farbstofftabellen, Berlin, 5th edition, 1914.
} 
The molecular weight, therefore, is uncertain, but it is in the neighborhood of 290.

The solution of dye is made up in gm. molecular concentrations taking the molecular weight as 290 . The fact that these concentrations are not precise, owing to uncertainty as to the molecular weight and as to the presence of impurities, does not interfere with the analysis of the data because the significant part of the analysis calls only for relative values. In order to keep these values constant, all the experiments were made with dye taken from the same stock bottle and when fresh solutions were made they were always checked with solutions previously made.

The dye was dissolved in $\frac{M}{150}$ phosphate buffer solutions, unless otherwise stated.

By the colorimetric method a range of concentrations of the dye between 0.00345 and $0.000017 \mathrm{M}$ may be measured. At the highest range it is possible to measure the difference between $0.0035 \mathrm{M}$ and $0.003 \mathrm{~m}$. At the lowest range it is possible to detect the difference between $0.000024 \mathrm{M}$ and $0.000017 \mathrm{M}$.

Every point in each curve is an average of one hundred experiments. All calculations were made with a 20 inch slide-rule.

The experiments were made at $25 \pm 0.5^{\circ} \mathrm{C}$. unless otherwise stated.

III.

Accumulation of the Dye with Different Outside Dye Concentrations at the Same $p H$ Value.

If, as stated in the writer's previous paper, ${ }^{6}$ we assume that the process of accumulation follows the formula for an irreversible pseudounimolecular reaction in which the dye combines with some constituent of the cell, we should expect that the equilibrium attained would be the same at all concentrations of external dye solutions of the same $\mathrm{pH}$ value.

To test this the cells were placed in different concentrations of cresyl blue (Grübler) at $\mathrm{pH} 6.9$.

${ }^{6}$ Irwin, M., J. Gen. Physiol., 1922-23, v, 727. 


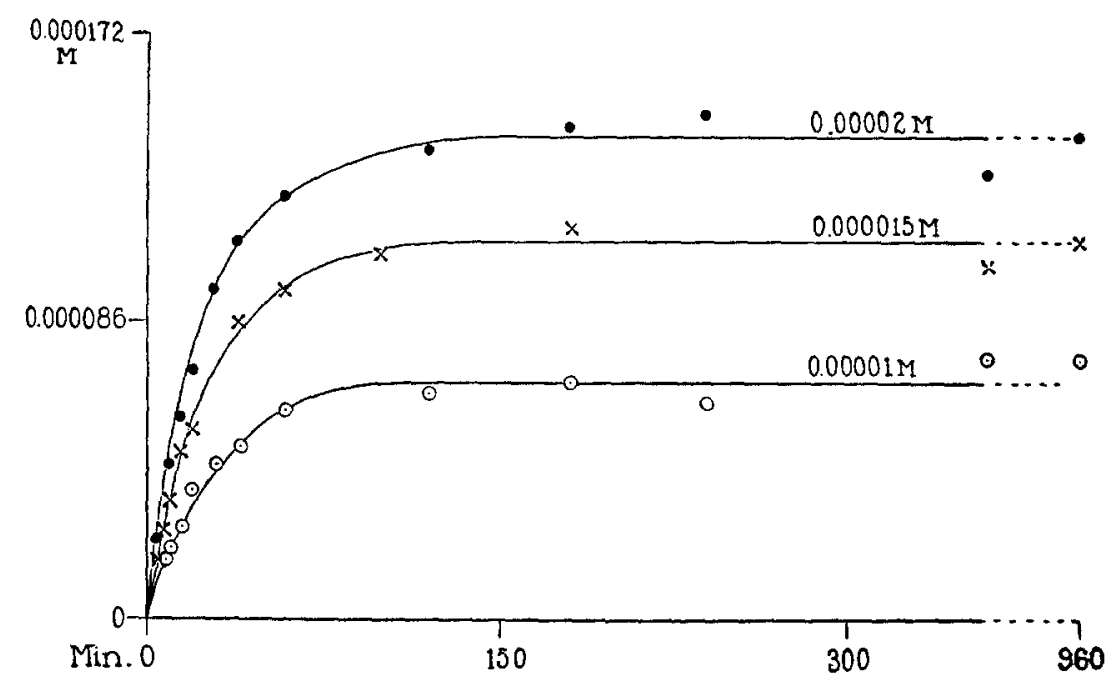

FIG. 1. Curves showing the accumulation of cresyl blue (Grübler) in the vacuole of living cells of Nitella in different concentrations of external dye solutions at pH 6.9 (at $25^{\circ} \mathrm{C}$ ) until equilibrium is reached. Abscissæ represent time and ordinates the concentration of the dye in the vacuole.

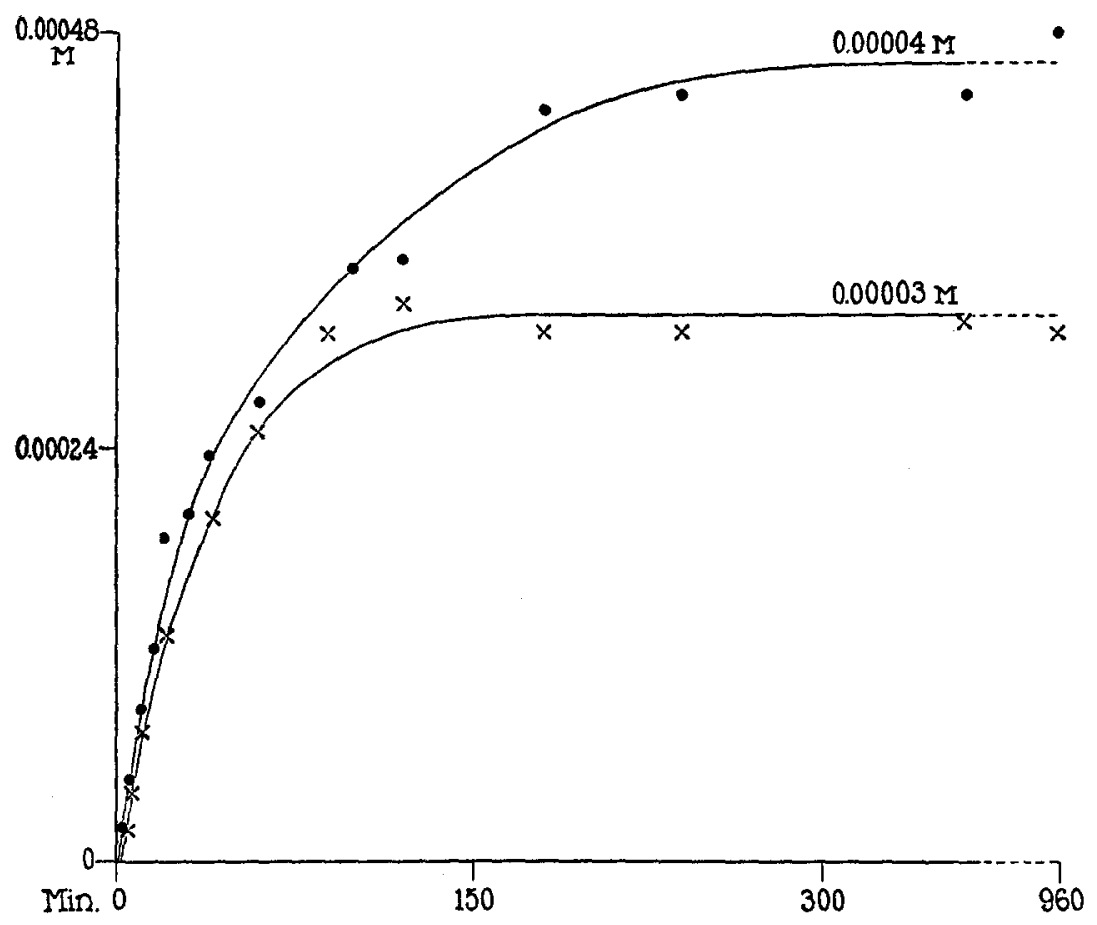

FIG. 2. Curves showing the accumulation of cresyl blue (Gribler) in the vacuole of living cells of Nitella in different concentrations of external dye solutions at $\mathrm{pH}$ 6.9 (at $25^{\circ} \mathrm{C}$.) until equilibrium is reached. Abscissæ represent time and ordinates the concentrations of the dye in the vacuole. 
With the solutions of dye at the molecular concentrations 0.00001 , $0.000015,0.00002,0.00003$, and 0.00004 , the accumulation continued until equilibrium was reached as shown in Figs. 1 and 2.

When the concentrations higher than $0.00004 \mathrm{M}$ were used, the cells died before the accumulation of the dye reached equilibrium (Fig. 3).

With an increase in the concentration of the outside dye solution ${ }^{7}$

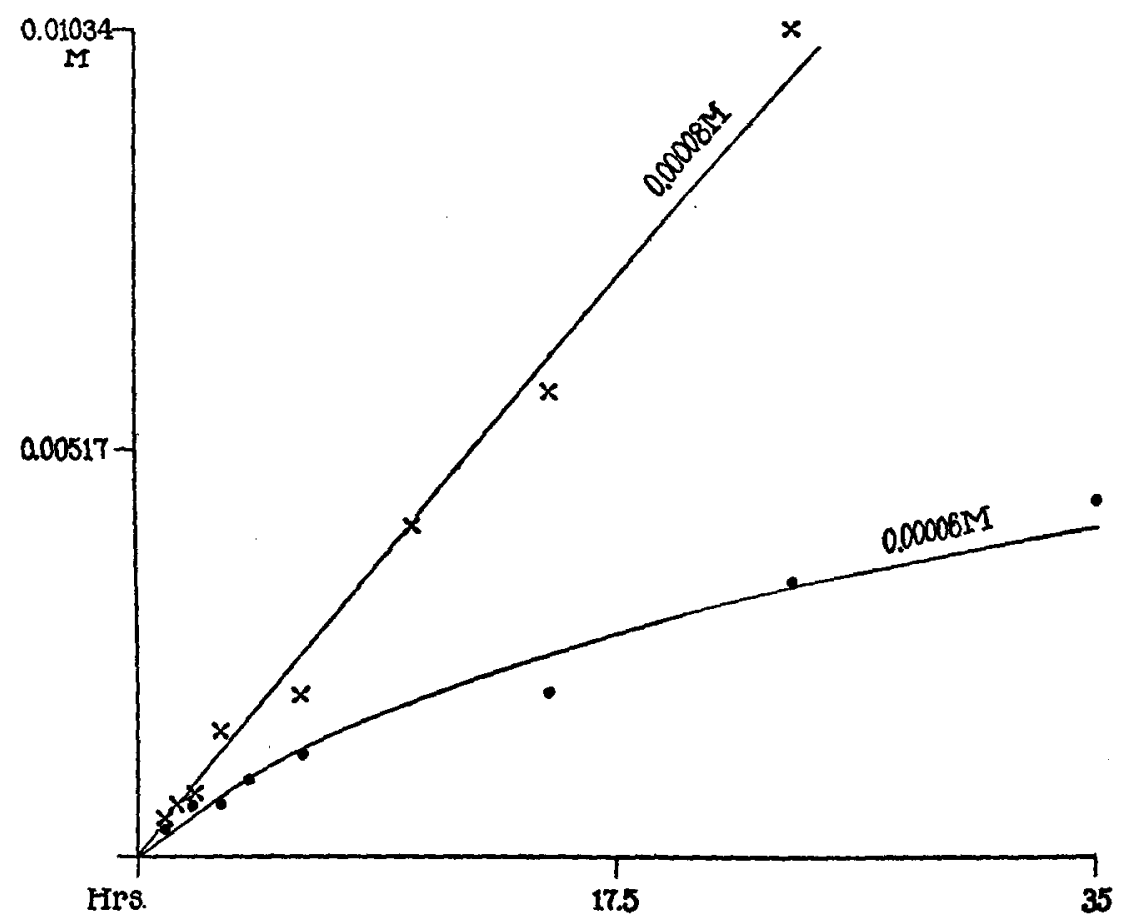

Frg. 3. Curves showing the accumulation of cresyl blue (Grübler) in the vacuole of living cells of Nitella in different concentrations of dye solutions at $\mathrm{pH} 6.9$ (at $25^{\circ} \mathrm{C}$.) until the death of the cells takes place. The absciss represent time and the ordinates the concentrations of dye in the vacuole.

${ }^{7}$ When the concentration of the dye solution reaches $0.0003 \mathrm{M}$, the $\mathrm{pH}$ of the buffer solution measurably decreases as the concentration of the dye solution increases. It is therefore necessary to determine carefully by means of the hydrogen electrode how much decrease is brought about at each concentration, and to dissolve the dye in a buffer solution of a higher $\mathrm{pH}$ value in order that the dye solution may have the desired $\mathrm{pH}$ value. The hydrogen electrode becomes poisoned by the dye when the concentration of the dye solution is above $0.002 \mathrm{M}$ 


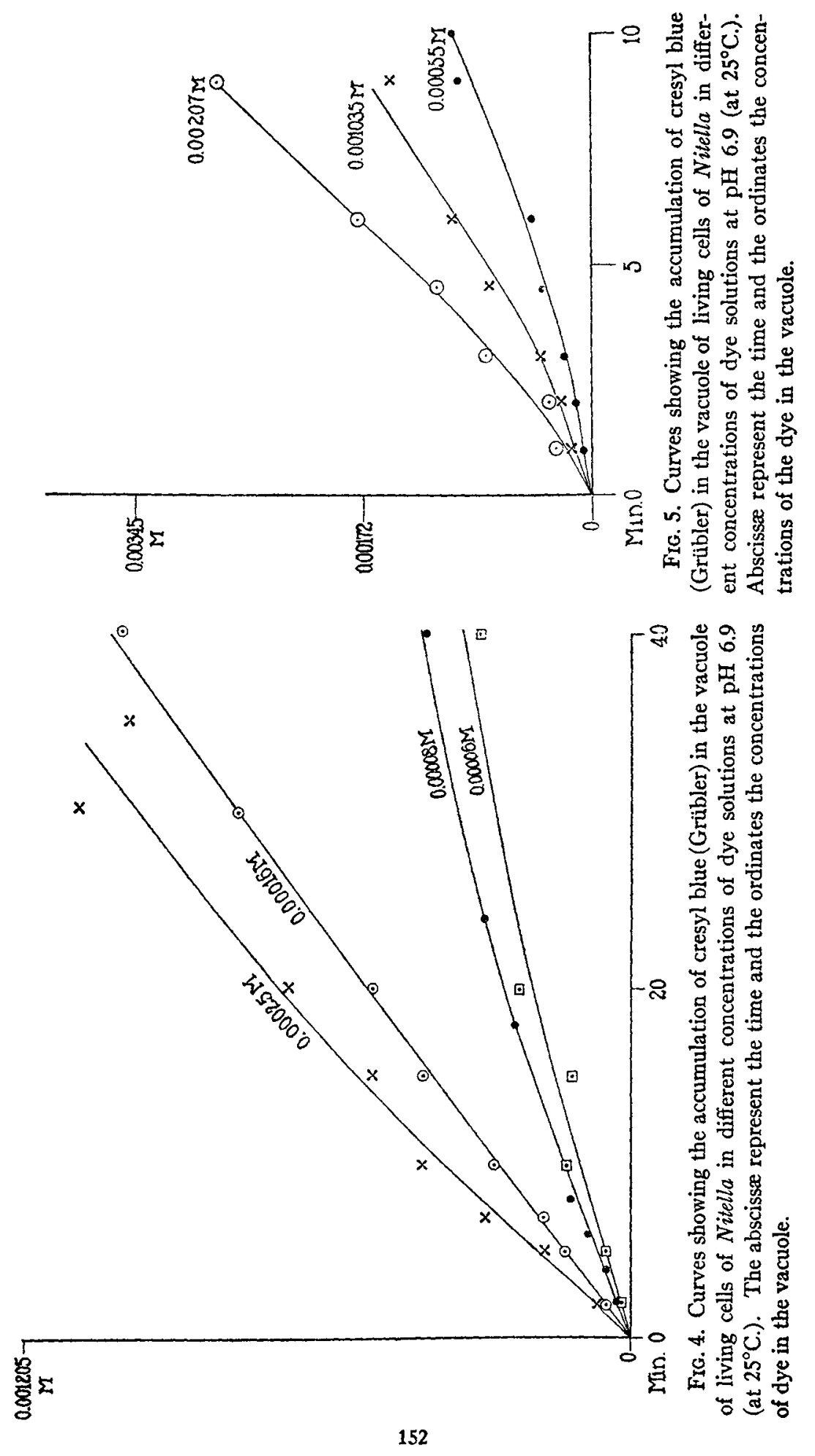


the rate of accumulation of the dye continued to increase as shown in Figs. 4 and 5.

IV.

\section{Analysis of the Time Curves.}

The above experiments show that the higher the concentration of the outside dye solution the higher is the level of equilibrium, which proves that the process of accumulation is reversible. The statement made in the previous paper by the writer as to the irreversibility of the process must therefore be revised, but the previous method of treating the time curves to obtain the constants is justified for the following reasons.

In the previous paper it was assumed that diffusion is more rapid than the chemical reaction, so that the rate was controlled by the dye (D) uniting with a cell constituent (A) according to the equation

$$
\mathrm{D}+\mathrm{A} \rightarrow \mathrm{DA}
$$

In the present paper this may be modified to

$$
\mathrm{D}+\mathrm{A} \rightleftarrows \mathrm{DA}
$$

Since the outside dye concentration remains constant during the reaction, the time curve may depend only on the values ${ }^{8}$ of $\mathrm{A}$ and DA and from this standpoint the reaction may be written $A \rightarrow D A$ representing a reversible pseudounimolecular process, just as in the case of the formation of ester when a very minute quantity of acid is added to a high concentration of alcohol in water. ${ }^{9}$

so that it is not possible to use concentrations beyond this. The writer wishes to thank Mr. E. S. Harris for his kindness in making determinations with the hydrogen electrode.

${ }^{8}$ With low concentrations of external dye solution the concentration of $\mathrm{A}$ at equilibrium is so much greater than that of DA that $A$ is practically constant during the reaction. In this case the forward reaction is practically of zero order, but the time curve follows the unimolecular reaction since the forward reaction is opposed by a reaction of the first order.

${ }^{9}$ Lewis, W. C. McC., A system of physical chemistry, New York and London, $1916, \mathrm{i}, 460$. 
If this supposition is correct we may treat the observed time curves in this paper by employing either the equation representing an irreversible unimolecular reaction, $\frac{d x}{d l}=k(a-x)$, (using for the value of $a$ the amount of substance transformed at equilibrium) or the equation for a reversible unimolecular reaction $\frac{d x}{d t}=k_{1}(a-x)-k_{2} x$ (using for the value of $a$, the initial concentration of substance).

This can be made clear by an illustration. Suppose we have an irreversible unimolecular reaction $\mathrm{A} \rightarrow \mathrm{B}$ with the velocity constant, $k=0.00407$, ceasing when 13.28 molecules of A have been transformed ${ }^{10}$ to $\mathrm{B}$. Let us make a time curve by finding the amount of $\mathrm{A}$ transformed at given times, using the equation:

$$
\frac{d x}{d t}=k(a-x)
$$

or, on integration,

$$
k=\frac{1}{t} \log \frac{a}{a-x}
$$

in which $a=$ amount of A transformed at equilibrium; $x=$ the amount of A transformed at the time $t$; and $k=$ the velocity constant of the reaction.

Let us now suppose that we have two opposing unimolecular reactions; the forward reaction, $\mathrm{A} \rightarrow \mathrm{B}$, with the velocity constant $k_{1}=$ 0.00296 , and the backward reaction, $\mathrm{B} \rightarrow \mathrm{A}$, with the velocity constant $k_{2}=0.00111$, starting with 18.23 molecules of $\mathrm{A}$ and ceasing when 13.28 molecules of $A$ have been transformed. Let us now find a time curve for this reaction by calculating the amounts of A transformed at the given times by the equation for a reversible unimolecular reaction:

$$
\frac{d x}{d t}=k_{1}(a-x)-k_{2} x
$$

or

$$
k_{1}+k_{2}=\frac{1}{t} \log \frac{K a}{K a-(K+1) x}
$$

\footnotetext{
10 The data used are obtained from the reaction described for the transformation of $\gamma$ oxybutyric acid into $\gamma$ butyro-lactone. Lewis, W. C. McC., A system of physical chemistry, New York and London, 1916, i, 185 and 460.
} 
in which $a=$ the initial concentration of $\mathrm{A} ; x=$ the amount of $\mathrm{A}$ transformed at the time $t ; k_{1}$ and $k_{2}$ are the velocity constants; and $K=$ $\frac{k_{1}}{k_{2}}$. When this is done we get precisely the same time curve as for the irreversible unimolecular reaction described above.

It is therefore evident that the same time curve may be regarded as expressing either a reversible or an irreversible unimolecular reaction. ${ }^{11}$ It was earlier regarded as irreversible because this was the simplest assumption to make at that time, but this in no way invalidated the analysis of the time curves in the former paper.

Because of its convenience the equation for the irreversible unimolecular reaction is used for the analysis of the time curves in this paper also.

Thus for the process $\mathrm{D}+\mathrm{A}=\mathrm{DA}$, we may use the equation:12

$$
\frac{d x}{d t}=k(a-x)
$$

or, on integration,

$$
k=\frac{1}{i} \log \frac{a}{a-x}
$$

in which $a=$ the amount of DA at equilibrium, and $x=$ the amount of $\mathrm{DA}$ at the time $t$, and $k=$ the velocity constant.

Table I shows that the values of $k$ thus obtained are fairly constant for each time curve at the concentrations $0.00001 \mathrm{M}, 0.000015 \mathrm{M}$, and $0.00002 \mathrm{~m}$. The values of $k$ for these three time curves are

"Mellor, J. W., Higher mathematics for students of chemistry and physics, London and New York, 4th edition, 1919, 228.

${ }^{12}$ In case we assume that the diffusion of the dye is slower than the chemical reaction, the same method of analyzing the time curves may be used as described in Section IV (on the basis of the chemical reaction being the slower process).

Since the concentration of the external dye solution is kept constant the rate of diffusion is found by measuring the rate of accumulation of the dye in the sap, and is represented by the equation

$$
\frac{d x}{d l}=k(s-x)
$$

in which $s=$ the amount of dye in the sap at equilibrium; $x=$ the amount of dye in the sap at the time $t$. 
practically the same (the average value is $k=0.0158$ ). If we assume the value of $k$ to be 0.0158 in all cases and calculate the values of $x$, we find this to be in fair agreement with the observed values of $x$ for each of these concentrations, as shown in Table $I$.

TABLE I.

Accumulation of brilliant cresyl blue in Nitella at $25^{\circ} \mathrm{C}$. The molecular concentrations are multiplied by $10 . .^{5}$ The process is represented by the equation: $k=\frac{1}{t} \log \frac{a}{a-x}$ in which $k$ is the velocity constant, $a$ is the concentration of dye in combination with the substances in the cell at equilibrium, and $x$ is the concentration of the dye in combination at the time $t$.

\begin{tabular}{|c|c|c|c|c|c|c|c|c|c|c|c|}
\hline \multicolumn{4}{|c|}{$\begin{array}{l}1 \mathrm{M} \text { external dye solution. } \\
\qquad a=6.9 \mathrm{M}\end{array}$} & \multicolumn{4}{|c|}{$\begin{array}{l}1.5 \mathrm{M} \text { external dye solution. } \\
\qquad a=11 \mathrm{M}\end{array}$} & \multicolumn{4}{|c|}{$\begin{array}{c}2 \text { M external dye solution. } \\
\qquad a=14.1 \mathrm{M}\end{array}$} \\
\hline$=$ & $\begin{array}{r}\dot{*} \\
\dot{0} \\
\dot{0} \\
\end{array}$ & 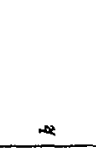 & 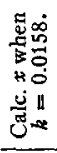 & $\Rightarrow$ & $\begin{array}{l}\dot{x} \\
8 \\
8 \\
\end{array}$ & $\approx$ & 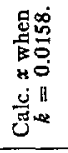 & $=$ & $\begin{array}{l}\dot{8} \\
\dot{0} \\
\dot{0}\end{array}$ & $*$ & 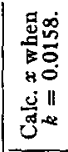 \\
\hline $\min$. & $x$ & & M & $\min$. & s. & & M & $\min$. & M & & $\mathbf{M}$ \\
\hline 8 & 1.7 & 0.0155 & 1.8 & 5 & 1.7 & 0.0144 & 1.9 & 5 & 2.4 & 0.0158 & 2.4 \\
\hline 10 & 2.1 & 0.0158 & 2.1 & 7 & 2.7 & 0.0177 & 2.4 & 10 & 4.5 & 0.0167 & 4.3 \\
\hline 15 & 2.8 & 0.0158 & 2.9 & 10 & 3.5 & 0.0167 & 3.4 & 15 & 5.9 & 0.0157 & 5.9 \\
\hline 20 & 3.8 & 0.0174 & 3.6 & 15 & 4.8 & 0.0167 & 4.6 & 20 & 7.2 & 0.0155 & 7.3 \\
\hline 30 & 4.5 & 0.0153 & 4.6 & 20 & 5.5 & 0.0151 & 5.7 & 30 & 9.7 & 0.0168 & 9.4 \\
\hline 40 & 5.0 & 0.0140 & 5.3 & 40 & 8.6 & 0.0165 & 8.4 & 40 & 11.0 & 0.0164 & 10.8 \\
\hline 60 & 6.0 & 0.0148 & 6.1 & 60 & 9.7 & 0.0155 & 9.8 & 60 & 12.4 & 0.0153 & 12.5 \\
\hline \multicolumn{2}{|c|}{ Average } & 0.0155 & & & & & 10.1 & \multicolumn{2}{|c|}{ Average... } & 0.0160 & \\
\hline & & & & \multicolumn{2}{|c|}{ Average. } & 0.0160 & & & & & \\
\hline
\end{tabular}

For higher concentrations the value of $k$ decreases. Thus for $0.00003 \mathrm{M}$ the average $k=0.0112$. Furthermore at $0.00004 \mathrm{M}$ there is a decrease in $k$ as the time increases, so that at the start $k=0.0106$ while toward the end of the process $k=0.0059$, as shown in Table II.

In higher concentrations the cells die before the reaction reaches an equilibrium, so that the true values of $\mathrm{DA}$ at equilibrium cannot be obtained. But if we take the maximum DA observed for each time 
curve as the value of $\mathrm{DA}$ at equilibrium, there is still more marked decrease in the value of $k$ than in the case of the lower concentrations of dye solutions.

The decrease in $k$ at higher concentrations may be attributed to secondary changes which take place in the cell after a certain amount of the dye has accumulated. If the process of accumulation were not disturbed by such changes, it might proceed in such a way that the

TABLE II.

Accumulation of brilliant cresyl blue in Nitella at $25^{\circ} \mathrm{C}$. The molecular concentrations are multiplied by 10.5 The process is represented by the equation: $k=\frac{1}{t} \log \frac{a}{a-x}$ in which $k$ is the velocity constant, $a$ is the concentration of the dye in combination with the substance in the cell at equilibrium, and $x$ is the concentration of the dye in combination at the time $t$.

\begin{tabular}{|c|c|c|c|c|c|}
\hline \multicolumn{3}{|c|}{$\begin{array}{l}3 \text { M external dye solution. } \\
\qquad a=32.1 \mathrm{M}\end{array}$} & \multicolumn{3}{|c|}{$\begin{array}{l}4.1 \mathrm{M} \text { external dye solution. } \\
\qquad a=46.6 \mathrm{M}\end{array}$} \\
\hline$t$ & obs. $x$. & $k$ & $t$ & obs. $x$. & $k$ \\
\hline min. & M & & $\min$ & $M$ & \\
\hline 3 & 2.2 & 0.0098 & 2 & 2.1 & 0.0106 \\
\hline 5 & 4.3 & 0.0129 & 5 & 5.0 & 0.0098 \\
\hline 10 & 7.6 & 0.0114 & 10 & 9.0 & 0.0093 \\
\hline 20 & 13.1 & 0.0114 & 15 & 12.4 & 0.0089 \\
\hline 40 & 20.0 & 0.0106 & 20 & 19.0 & 0.0114 \\
\hline 60 & 25. 2 & 0.0111 & 30 & 20.3 & 0.0081 \\
\hline \multicolumn{2}{|l|}{ Average.. } & 0.0112 & $\begin{array}{r}60 \\
100\end{array}$ & $\begin{array}{l}23.5 \\
34.5\end{array}$ & $\begin{array}{l}0.0051 \\
0.0059\end{array}$ \\
\hline
\end{tabular}

value of $k$ would be constant (at about 0.0158 ) at all concentrations of the external dye solution, just as in the lower concentrations where the reaction reaches an equilibrium without any decrease in the values of $k$.

In the case of $0.00003 \mathrm{M}$ and $0.00004 \mathrm{M}$ outside solutions the time curve seems to come to equilibrium but this appearance is deceptive. In reality the secondary changes are slowly taking place and the curve is slowly rising so that no true equilibrium is reached. This is more 
pronounced at higher concentrations, where the accumulation of DA continues to take place until the death of the cell and the time curves give straight lines. At still higher concentrations of external dye solutions, these changes are beginning to take place more rapidly so that the shape of the time curve is no longer concave to the abscissa but convex, as is shown by comparing Figs. 1 to 5 . The nature of such changes is discussed in the next section.

$\mathrm{v}$.

Analysis of the Relation between the Concentration of the Dye in the Sap and That of the External Dye Solution at Equilibrium.

Heretofore the accumulation of the dye in the cell sap has been expressed by the equation:

$$
\mathrm{D}+\mathrm{A}=\mathrm{DA}
$$

without stating whether $\mathrm{D}$ consists of $\stackrel{+}{\mathrm{D}}$ ions, dye salt, or dye hydrate (all of these taken together we may call the total dye for convenience). To explain the above reaction we may consider the following alternatives.

(1) When D represents the total dye, and A represents weak acids, proteins, or their salts.

(2) When $\mathrm{D}$ represents the dye hydrate $(\mathrm{DOH})$, and $\mathrm{A}$ represents weak acids, proteins, or their salts.

If $\mathrm{D}$ represented the total dye, the equation may be written:

$$
\mathrm{DS}+\mathrm{XA}=\mathrm{DA}+\mathrm{XS}
$$

in which DS is the total dye and XA is the substance in the cell (weak acids, proteins, or their salts).

If we assume that XS can be eliminated from the equation because it is already present in excess in the cell, and that DA is slightly ionized or slightly soluble, then according to the law of mass action the relation at equilibrium is represented by the equation:

$$
\frac{(\mathrm{DS})_{e}(\mathrm{XA})_{e}}{(\mathrm{DA})_{e}}=K
$$

in which $K$ is the equilibrium constant and the subscript $e$ denotes the 
concentration at equilibrium. When we solve for $(\mathrm{DA})_{e}$ by putting $K=0.0024 ;(\mathrm{XA})_{s}$, the concentration of XA at the start, $=0.017 \mathrm{M}$; and $(\mathrm{XA})_{e}=(\mathrm{XA})_{s}-(\mathrm{DA})_{e}$, we find that the observed values agree with the calculated until 0.00002 outside dye concentration is reached, beyond which the observed values are higher than the calculated, as shown in Fig. 6, A.

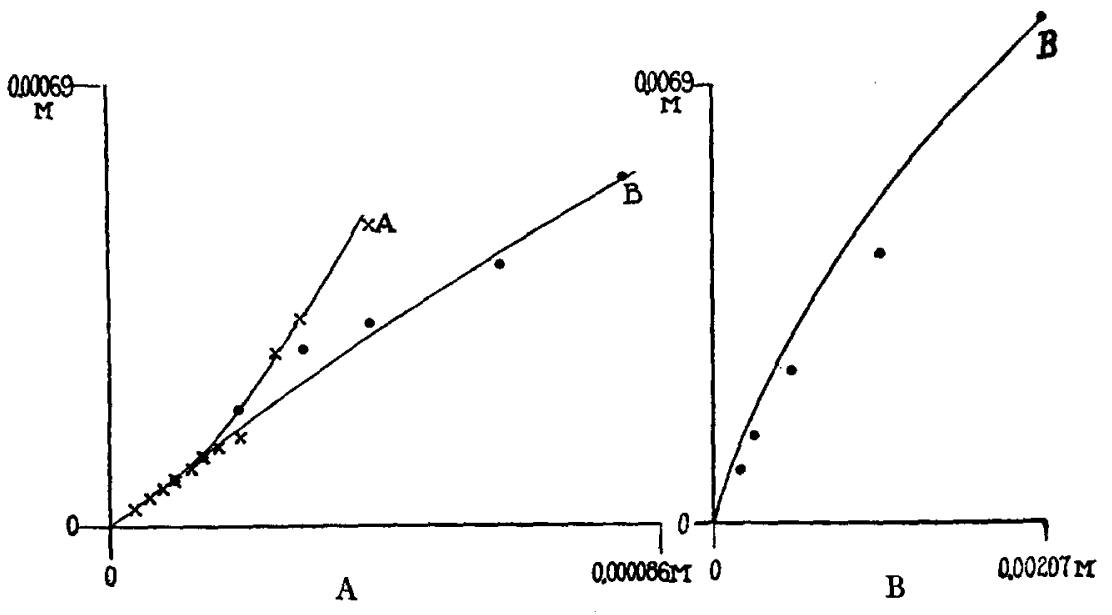

FIGs. 6, A and 6, B. Curves showing the relation of the concentrations of cresyl blue (Grübler) in the vacuole of living cells of Nitella at equilibrium to the concentrations of outside dye solutions at $\mathrm{pH}$ 6.9. The abscissæ represent the concentrations of the outside dye solutions, and the ordinates the concentrations of the dye in the vacuole.

In Fig. 6, A Curve A shows the observed equilibria. In Curve B the symbol (•) represents the equilibria calculated from $\frac{d x}{d t}$. The curve as drawn shows the theoretical equilibria, when $\mathrm{XA}=0.017 \mathrm{M}$ and $K=0.0024$.

Fig. 6, B extends Curve B (of Fig. 6, A) to higher concentrations.

By changing the values of $(\mathrm{XA})_{s}$ and $K$, we are able to raise the calculated value of $(\mathrm{DA})_{e}$ at higher concentrations of dye, but the shape ${ }^{13}$

${ }^{13}$ If we represent the reaction by the equation

$$
2 \mathrm{DS}+\mathrm{X}_{2} \mathrm{~A}=\mathrm{D}_{2} \mathrm{~A}+2 \mathrm{XS}
$$

and at equilibrium write 
of the observed curve is so different from the theoretical that it is not possible to make them agree.

The disagreement between calculation and observation may be due to changes brought about by certain processes which take place in the cell as soon as the concentration of dye in the sap reaches a certain value.

These processes apparently consist in secondary changes, possibly associated with preliminary stages of injury, which disturb the normal . course of events as already stated in Section IV. It is a simple matter to calculate what the equilibria would be if this disturbance did not occur. Theoretically, if all the curves reached equilibrium at practically the same time (and inspection of the time curves shows this to be approximately true), and if all obey the same formula (e.g., represent reversible unimolecular reactions) it is evident that the values for $\frac{d x}{d t}$ for all of the curves taken at any given time will be proportional to the final equilibria attained. Thus if at three minutes ${ }^{14} \frac{d x}{d t}$ for

$$
\frac{(\mathrm{DS})_{e}^{2}\left(\mathrm{X}_{2} \mathrm{~A}\right)_{e}}{\left(\mathrm{D}_{2} \mathrm{~A}\right)_{e}^{2}}=K
$$

and solve for $\left(D_{2} A\right)_{e}$ we find that the calculated values of $\left(D_{2} A\right)_{e}$ agree with those of the observed. This equation seems at present to be merely empirical for the following reason. For the analysis of the time curves, the same equation $\frac{d x}{d t}=k(a-x)$ can be applied, whether we use $2 \mathrm{DS}$ and $\mathrm{X}_{2} \mathrm{~A}$ or DS and XA, since the concentration of DS remains constant throughout the reaction for each time curve. Therefore the only way one can interpret the observed change in the shape of the time curves from convex to concave as the concentration of the external dye solution increases is by assuming that the secondary changes occur in the cell, which increase the formation of DA.

The same equation may be used in case DS is replaced by DOH (dye hydrate).

${ }_{14} \frac{d x}{d t}$ at 1 minute, and 2 minutes, gives the same type of curve. Rates taken for $0.0000173 \mathrm{M}$ and $0.0000346 \mathrm{M}$ dye in the sap give the same type of curve.

Since the range of the concentrations of external dye solutions used is very large, it is not possible to obtain $\frac{d x}{d t}$ at an initial stage of the reaction for the higher concentration of dye when a considerable amount of DA must enter the 
Curve I is 1 , and for Curve II is 2 , the final equilibrium of Curve I is one-half that of Curve II.

It would therefore seem that if the final equilibrium is altered by some secondary process which sets in toward the latter part of the reaction we can approximate the value which would be obtained if the secondary process did not occur by taking $\frac{d x}{d t}$ during the very first part of the curve before any deviations from the normal take place. The equilibria calculated by taking $\frac{d x}{d t}$ at three minutes for all the concentrations of outside dye solution, represented by the symbol (•) are shown in Figs. 6, A and 6, B and are in good agreement with the theoretical curve.

The experiments do not show whether (DA)e reaches a maximum because it is not possible to use an external dye solution above the concentration of $0.002 \mathrm{M}$, for the reason already mentioned. It is therefore difficult to tell what this maximum would be, but when $(\mathrm{XA})_{s}$ is equal to $0.017 \mathrm{M}$, the theoretical curve fits the observed fairly well, so that the maximum of $(\mathrm{DA})_{e}$ may be assumed to be in the neighborhood of $0.017 \mathrm{M}$.

According to the above assumptions if we increase the external concentration until practically all of XA is combined with the dye any further increase in the external concentration will have practically no effect.

The analysis therefore seems to indicate that there is a slow increase in the substance combining with the dye as the dye accumulates in the cell vacuole, which may be a preliminary stage of injury.

The assumption that the total dye unites with the cell substance may not be the best explanation for the following reason. It has been found in the writer's experiments ${ }^{15}$ on the partition of the dye between

sap even in 1 minute. For this reason the values obtained for $\frac{d x}{d t}$ as a possible means of calculating the concentrations of DA at equilibrium are approximate, but it seems that the error is small, so that they may be used as approximate values.

${ }^{15}$ At $22^{\circ} \mathrm{C}$., $1 \mathrm{cc}$. of pure chloroform was placed in each $100 \mathrm{cc}$. of dye solutions $(0.000345 \mathrm{M}$ ) at different $\mathrm{pH}$ values (from $\mathrm{pH} 6$ to $\mathrm{pH} 9.1$ ). The greater the 
chloroform and water, that the concentration of the undissociated molecule, $\mathrm{DOH}$, increases with an increase in the $\mathrm{pH}$ value of the dye solution, and that the dissociation constant of $\mathrm{DOH}$ is about $10^{-6.4}$. The concentration of dye in the cell sap increases with that of DOH in the external solution in a manner indicating that the dye enters the cell only in the form of undissociated DOH. We may therefore assume that $\mathrm{DOH}$ enters and that $\stackrel{+}{\mathrm{D}}$ ion combines in the cell with some organic anion.

1. If we assume that $\mathrm{DOH}$ combines with weak acids or proteins the process may be represented by the reaction:

$$
\mathrm{DOH}+\mathrm{HA}=\mathrm{DA}+\mathrm{H}_{2} \mathrm{O}
$$

in which $\mathrm{DOH}$ is the dye hydrate and HA is the weak acid or proteins.

Then the condition at equilibrium, according to the law of mass action, may be represented by the following equation, provided DA is slightly soluble or slightly ionized:

$$
\frac{(\mathrm{DOH})_{e} \times(\mathrm{HA})_{e}}{(\mathrm{DA})_{e}}=K
$$

in which $(\mathrm{HA})_{e}=$ concentration of free acid and $(\mathrm{DOH})_{e}=$ concentration of free base. The subscript $e$ denotes the concentrations at equilibrium.

2. In case it is a salt with which $\mathrm{DOH}$ predominantly combines the

$\mathrm{pH}$ value of the aqueous dye solution, the greater was the accumulation of dye in chloroform, until a maximum was reached, beyond which further increase in the pH value brought about no increase in the accumulation of the dye. At this point the dye was regarded to be completely changed to $\mathrm{DOH}$ and the per cent of $\mathrm{DOH}$ at lower $\mathrm{pH}$ values was calculated on this basis. When different concentrations of aqueous dye solutions were used at $\mathrm{pH} 6.9$, it was found that in the range of concentrations from $0.00002 \mathrm{M}$ to $0.000345 \mathrm{M}$ a straight line is obtained when the concentration at equilibrium of $\mathrm{DOH}$ in chloroform is plotted as ordinates and concentration of DOH in the aqueous solution as abscissa, thus showing that the amount of $\mathrm{DOH}$ is not appreciably changed at these concentrations. A detailed account of the experiments will be published later. 
same analysis will apply. The reaction may be represented by the equation: ${ }^{10}$

$$
\mathrm{DOH}+\mathrm{RCHOH} \cdot \mathrm{COONa}=\mathrm{R} \cdot \mathrm{CHOD} \cdot \mathrm{COONa}+\mathrm{H}_{2} \mathrm{O}
$$

just as in the case of copper in combination with sodium tartrate.

If we substitute MA for $\mathrm{R} \cdot \mathrm{CHOH} \cdot \mathrm{COONa}$ and $\mathrm{MAD}$ for $\mathrm{R} \cdot \mathrm{CHOD} \cdot \mathrm{COONa}$ and if MAD is slightly ionized or slightly soluble, then at equilibrium the condition may be represented by the equation:

$$
\frac{(\mathrm{DOH})_{e}(\mathrm{MA})_{6}}{(\mathrm{MAD})_{e}}=K
$$

in which $K=$ the equilibrium constant and the subscript $e$ denotes the concentrations at equilibrium.

Since we do not know exactly what is the predominant substance in the cell that combines with $\mathrm{DOH}$ let us for convenience write the equation as follows:

$$
\mathrm{DOH}+\mathrm{XA}=\mathrm{DA}+\mathrm{XOH}
$$

in which XA is any substance possessing anions capable of combining with $\stackrel{+}{D}$ ions. If we eliminate $\mathrm{XOH}$ from the equation by assuming that it is a substance which is already in excess in the cell, then at equilibrium the reaction is represented by the equation:

$$
\frac{(\mathrm{DOH})_{e}(\mathrm{XA})_{e}}{(\mathrm{DA})_{e}}=K
$$

${ }^{16}$ The reaction may be represented by another equation:

$$
\mathrm{DOH}+\mathrm{MA}=\mathrm{DA}+\mathrm{MOH}
$$

in which $M$ is any kation except hydrogen, $M A$ is the salt, and $D A=$ the dye compound formed which is slightly soluble or slightly ionized. We may then write

$$
\frac{(\mathrm{DOH})_{e}(\mathrm{MA})_{e}}{(\mathrm{DA})_{e}(\mathrm{MOH})_{e}}=K
$$

This equation does not fit the facts unless we eliminate $\mathrm{MOH}$ and write

$$
\frac{(\mathrm{DOH})_{e}(\mathrm{MA})_{e}}{(\mathrm{DA})_{e}}=K
$$

in which subscript $e$ denotes the concentrations at equilibrium. Whether this elimination can be justified is uncertain. 
Since apparently DOH molecules alone can enter the cell, the concentration of undissociated $\mathrm{DOH}$ molecules in the cell at equilibrium is assumed ${ }^{17}$ to be equal to that in the external dye solution.

It is not difficult to find the concentration of $(\mathrm{DOH})_{e}$ since from the dissociation curve of $\mathrm{DOH}$ obtained by the writer's experiments ${ }^{15}$ on the coefficient of partition of the dye between chloroform and water, it is found that there are present about 13 per cent undissociated $\mathrm{DOH}$ molecules at $\mathrm{pH} 6.9$ (in all the concentrations of external dye solutions employed), and the actual molecular concentration of $\mathrm{DOH}$ in the external dye solution may be calculated. Since DOH in the sap is assumed to be equal to $\mathrm{DOH}$ in the outside dye solution the above concentration obtained for $\mathrm{DOH}$ is the value used for $(\mathrm{DOH})_{e}$ in the equation.

Since we suppose $\mathrm{DOH}$ and DA to have the same color $^{18}$ the concentration of $(\mathrm{DA})_{e}$ is obtained by subtracting from the concentration of dye in the sap at equilibrium (determined colorimetrically) the concentration of $(\mathrm{DOH})_{e}$.

If we put $(\mathrm{XA})_{s}=$ the concentration of $\mathrm{XA}$ at the start, then $(\mathrm{XA})_{e}=(\mathrm{XA})_{s}-(\mathrm{DA})_{e}$.

If we put $(\mathrm{XA})_{s}=0.017 \mathrm{M}$ and $K=0.0003$ and solve for (DA)e at different concentrations of dye we obtain Curve B in Figs. 7, A and $7, \mathrm{~B}$; the calculated Curve $\mathrm{B}$ agrees with the observed Curve $\mathrm{A}$ until the concentration of $\mathrm{DOH}$ in the external dye solution is $0.0000022 \mathrm{M}$, above which the calculated $(\mathrm{DA})_{e}$ is less than the observed.

If we compare the calculated values of $(\mathrm{DA})_{e}$ with the $(\mathrm{DA})_{e}$ calculated from the observed values of $\frac{d x}{d t}$ (as already described), we find that the calculated agrees well with the observed, as shown by

${ }^{17}$ There may be a difference in the solubility of $\mathrm{DOH}$ in the constituents of the cell and in the outside dye solution, but since this difference if it exists will be constant for all values of $(\mathrm{DA})_{e}$ obtained, it will not disturb the fundamental analysis of the curve, though it will change the value of the assumed equilibrium constant.

${ }^{18}$ There is experimental evidence for this. If we have two capillary tubes of identical length and size, half filled with a dye solution, and if we fill the second half of one tube with the cell sap, and that of the second tube with a buffer solution of any $\mathrm{pH}$ value between $\mathrm{pH} 5$ and 9 , the color of the tubes will be the same, provided the contents of each tube are carefully mixed. 
the Curve $B$ representing the calculated curve and the symbol $(X)$ representing the values of $(\mathrm{DA})_{e}$, in Figs. $7, \mathrm{~A}$ and $7, \mathrm{~B}$.

When the analysis was repeated with the National Aniline Chemical Company's dye the theoretical curve ${ }^{19}$ was found to fit the observed $(\mathrm{DA})_{e}$ (obtained from $\frac{d x}{d t}$ as before) fairly well when $(\mathrm{XA})_{s}$ equals 0.017 , and $K=0.00417$ as shown in Fig. 8 .

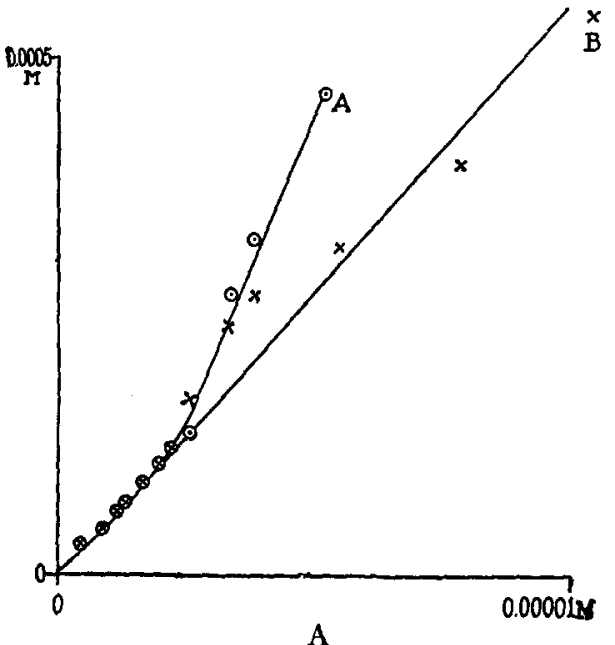

A

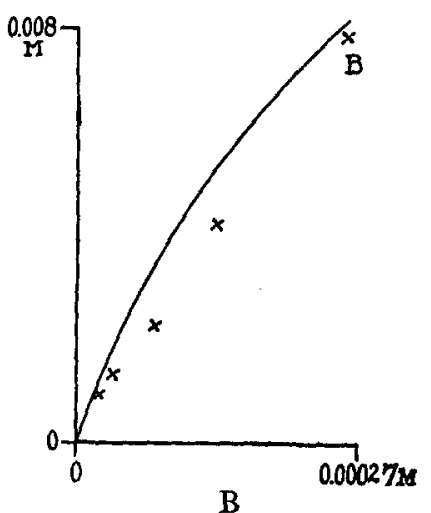

B

Figs. 7, A and 7, B. Curves showing the relation between the dye bydrate $(\mathrm{DOH})$ and $(\mathrm{DA})_{e}$ (the dye compound) in the sap at equilibrium. The concentrations of $\mathrm{DOH}$ are plotted as abscisse and those of $(\mathrm{DA})_{e}$ as ordinates.

The symbol $\times$ represents $(D A)_{e}$ calculated from $\frac{d x}{d t}$. Curve $A$ represents the observed (DA $)_{\epsilon}$; and Curve $B$ as drawn represents the calculated $(D A)_{e}$, when $\mathrm{XA}=0.017 \mathrm{M}$ and $K=0.0003$.

Fig. 7, B shows Curve B (of Fig. 7, A) carried to higher concentrations.

${ }^{19}$ In case of the National Aniline Chemical Company dye the same stock of dye was no longer to be had so that it was not possible to find the dissociation constant of the dye by the method described in Foot-note 15. Therefore DOH here is represented by the total concentration of dye $(+-D, D$, and $D O H)$, but this will not invalidate the calculation, since in all probability (just as in the case of the Gruibler dye), the percentage of undissociated molecules of DOH is constant throughout the range of concentrations of external dye solutions.

It must be remembered here that the final amount of XA or the value of $K$ is 
The writer has made calculations on various other hypotheses ${ }^{20}$ but none of them fits the facts as well as the one just proposed; this will therefore be adopted as a working hypothesis and will be again referred to under the heading "Theoretical Discussion."

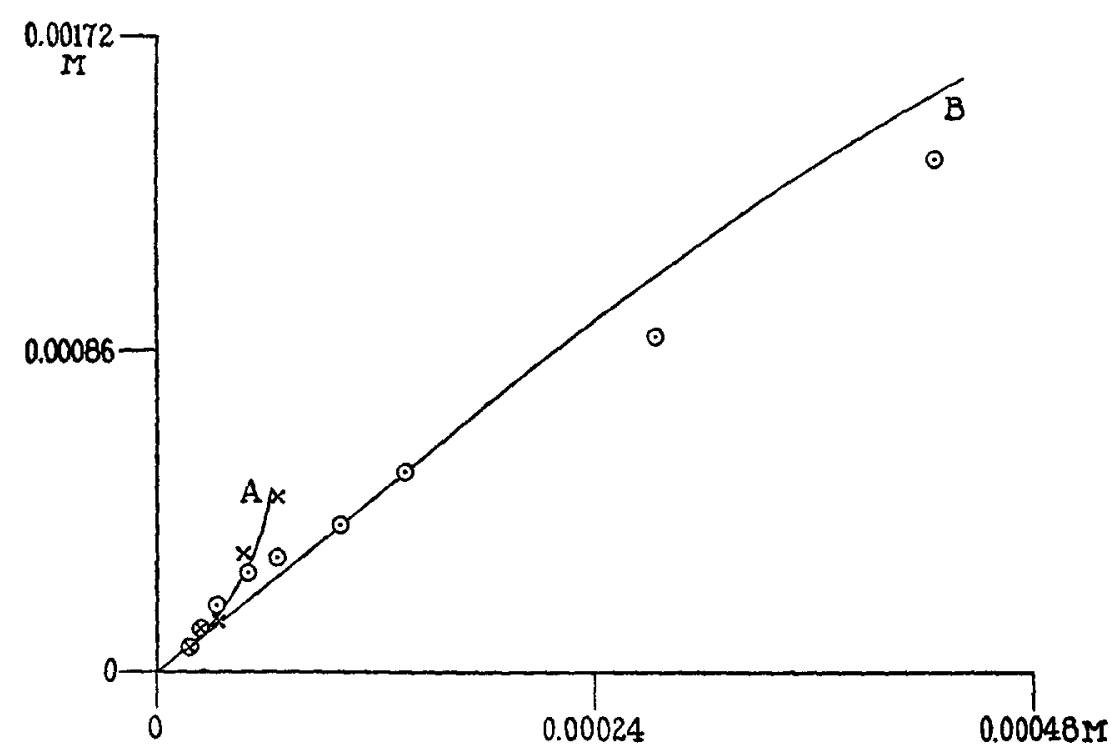

Fig. 8. Curves showing the relations of the equilibria reached with cresyl blue (National Aniline Chemical Company) to the concentrations of the outside dye solutions at $\mathrm{pH}$ 7.3. Abscissa represent the concentrations of the outside dye solutions and ordinates the concentration of the dye in the vacuole at equilibrium.

Curve A shows the observed equilibria. The symbol $\odot$ shows the equilibria calculated from the observed values of $\frac{d x}{d t}$. and Curve $\mathrm{B}$ as drawn shows the theoretical equilibria where $(\mathrm{XA})_{s}=0.017 \mathrm{M}$ and $K=0.00417$.

of no great interest; the importance lies in knowing the relative proportions of (DA), at different concentrations of dye, in order to analyze the nature of the process of accumulation. This relative proportion is not disturbed as long as the shape of the curve remains the same. Since the shape of the curve is the same with both makes of dye the analysis is not interfered with by the difference in the speed of accumulation, and therefore, the relative proportions of the values of DA obtained will not be disturbed.

${ }^{20} a$. Calculation was made on the assumption that DA is largely ionized where the equation used is:

$$
\mathrm{DOH}+\mathrm{HA}=\mathrm{D}+\mathrm{A}+\mathrm{H}_{2} \mathrm{O}
$$


VI.

\section{Relation of Equilibria to the Concentration of Outside Buffer Solutions} in Which the Dye Is Dissolved.

Since it is often stated ${ }^{21}$ that the addition of salts (especially $\mathrm{Na}_{2} \mathrm{HPO}_{4}$ ) affects the taking up of dye by substances it is of interest to make up the dye in two different concentrations of buffer solutions. In the experiments described in Section III the solutions were made up by

and at equilibrium $\frac{(\mathrm{DOH})_{e}(\mathrm{HA})}{(\mathrm{DA})_{e}^{2}}=K$, but the agreement is not good.

$b$. Since the cell may contain predominantly dibasic acids, such as malic, tartaric, and carbonic, and tribasic acid such as citric, this must be considered in case the dissociation of the second $\vec{H}$ ion enters into the reaction. The analysis was made with this in view by using the equation: $2 \mathrm{DOH}+\mathrm{H}_{2} \mathrm{~A}=\mathrm{D}_{2} \mathrm{~A}+\mathrm{H}_{2} \mathrm{O}$.

$$
\frac{4(\mathrm{DOH})_{e}^{2}\left(\mathrm{H}_{2} \mathrm{~A}\right)_{e}}{(\mathrm{DA})_{c}^{3}}=K(\text { in case } \mathrm{DA} \text { is dissociated) }
$$

and

$$
\frac{4(\mathrm{DOH})_{e}^{2}\left(\mathrm{H}_{2} \mathrm{~A}\right)_{e}}{(\mathrm{DA})_{0}}=K\left\{\begin{array}{l}
\text { in case } \mathrm{DA} \text { is either slightly soluble } \\
\text { or slightly dissociated }
\end{array}\right\}
$$

but the theoretical values of DA did not agree with the observed.

c. Combination of $\mathrm{DOH}$ with a strong acid such as $\mathrm{HCl}$ would give an equation which fits, i.e.

$K=\frac{(\mathrm{DOH})_{e}(\mathrm{HA})_{e}}{(\mathrm{DA})_{e}}$ but we cannot assume such a combination, since the $\stackrel{+}{\mathrm{H}}$ ion concentration of the sap is $10^{-5 \cdot 6}$, which is too low to account for the reaction in case $\mathrm{HCl}$ is regarded as responsible for the $\mathrm{pH}$ value of the sap.

d. Analysis on the basis of Donnan equilibrium is unsatisfactory because the conditions in the cell are not yet sufficiently known. The following difficulties at once present themselves. It is probable that both the inner and outer layers of the cell are semipermeable. It seems that none of the constituents of the sap come out from the vacuole of a normal cell, and mostly the undissociated molecules seem to be able to penetrate the cell. For this reason it does not seem possible to make any analysis on the basis of the Donnan equilibrium. If we boldly assume that the accumulation of the dye is dependent on the Donnan effect, that the 
diluting ten-fold the $\frac{\mathrm{M}}{15}$ phosphate buffer solutions at $\mathrm{pH} 6.6$; for the present experiment $\frac{\mathrm{M}}{15}$ phosphate buffer solution of the same $\mathrm{pH}$ was diluted fifty times. The $\mathrm{pH}$ value ${ }^{22}$ of the $\frac{\mathrm{M}}{150}$ buffer solution is 6.9 , while that of $\frac{\mathrm{M}}{500}$ is about 7.05 .

conditions such as $\mathrm{H}$ ion concentrations in the sap, and in the outside solutions $+$

remain unchanged, and that there are $\mathrm{D}$ ions inside the sap and outside the cell (the protoplasm and the inner layer are ignored), then we find that the ratio $\frac{D_{1}}{D_{0}}$ (in which $D_{1}=$ the $D$ ions in the sap and $D_{0}=$ the $D$ ions outside) is constant, which agrees very well with the facts for the range of external dye solutions $0.000004 \mathrm{M}$ to $0.00002 \mathrm{M}$, assuming $\frac{D_{1}}{D_{0}}$ to be approximately 7 but above this concentration the ratio increases, until finally we find that no equilibrium is reached before the cell dies. This increase in the ratio may be attributed to secondary changes as mentioned above.

$e$. If the process is governed primarily by adsorption, the accumulation must follow the adsorption formula $y=k C^{\frac{1}{n}}$ in which $y$ is the concentration of the dye in the sap at equilibrium (DA)e and $C$ is the concentration of the outside dye solution (DY) $)_{e}$ at equilibrium; while $k$ and $n$ are constants. If the process follows this equation, $\log$ (DY). plotted against log (DA), should give a straight line. It is evident from Figs. 6, 7 and 8 that the curves of observed equilibria cannot be interpreted as due to adsorption since they are convex toward the abscissa. It might be thought that if we use the observed equilibria undisturbed by the secondary process (which increases accumulation) the agreement with the adsorption formula might be better. It is found, however, that although $\log$ (DA). plotted as ordinates against $\log$ (DY) as abscissæe give an approximately straight line for the first part of the curve, the slope of this line is about $45^{\circ}$, which is not what would be expected for adsorption.

If we calculate (DA)。 from the observed $\frac{d x}{d t}$ we must use another formula (since the process reaches a maximum) such as

$$
\log \frac{\mathrm{S}}{\mathrm{S}-a}+\mathrm{A} a=\frac{1}{k} c
$$




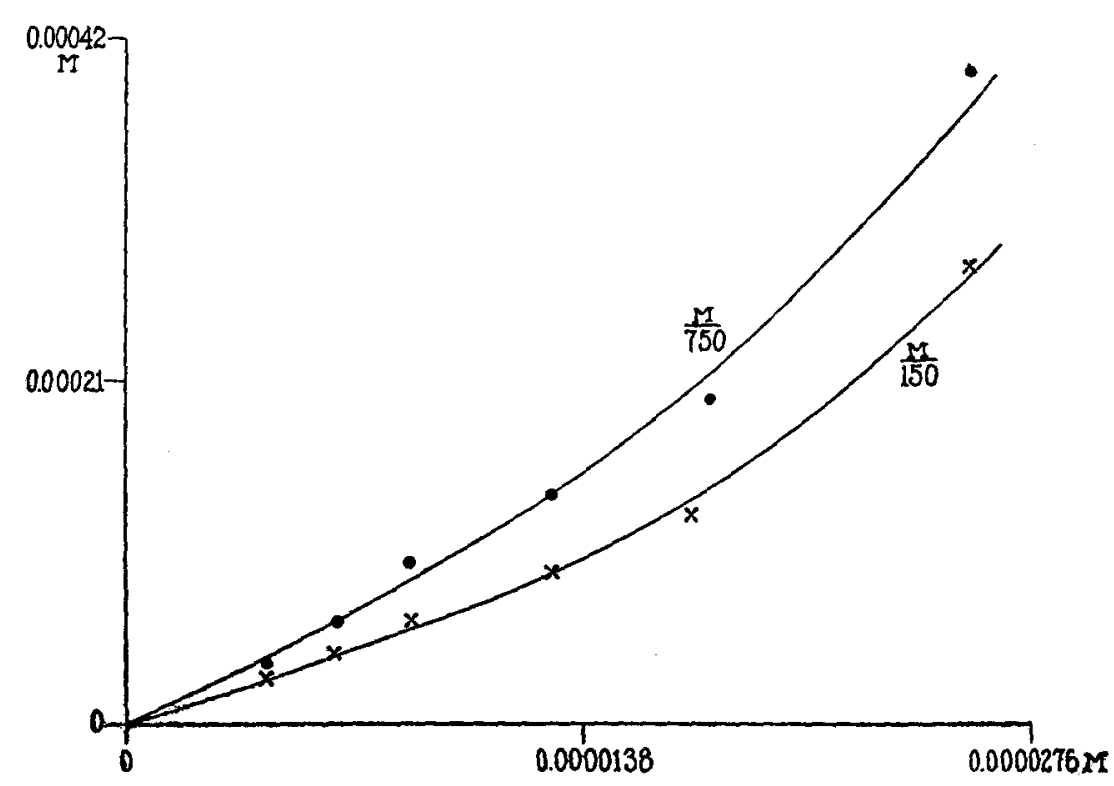

FIG. 9. Curves showing the difference in the equilibria when two dilutions of buffer solutions are used, $\frac{M}{150}$ and $\frac{M}{750}$. The abscissæ represent the outside dye concentrations (Grübler) and the ordinates the inside dye concentrations at equilibrium.

where $a$ is $(\mathrm{DA})_{e}, c$ is $(\mathrm{DY})_{e}$, and $\mathrm{S}$ is the maximum value of the substance adsorbed; $A$, and $K$ are constants.

Arrhenius found that the product AS was nearly constant (about 0.4343 ) for the data obtained by Schmidt on experiments with various substances.

This value (0.4343) is used for AS while we put $S=0.017$ to calculate the value of $A$ in the equation given above for the accumulation of dye in the cell vacuole. The values of $k$ obtained by this method are roughly constant. As Arrbenius says, this formula is not very satisfactory because it has three constants to be determined for which reason it has only the value of an interpolation formula. See Schmidt, G. C., Z. physik. Chem., 1910, lxxiv, 689. Arrhenius, S., Theories of solutions, New Haven, 1912, 55.

${ }^{21}$ Bancroft, W. D., Applied colloid chemistry, New York and London, 1st edition, 1921, 116.

${ }^{22}$ The $\mathrm{pH}$ value was determined by colorimetric methods by means of neutral red which was used because there was no salt error at these concentrations of buffer solutions. Cf. Prideaux, E. B. R., The theory and use of indicators, New York, 1917, 223. 
With outside dye solutions (Grübler) $0.0000043,0.0000065$, $0.0000086,0.000013,0.000017$, and $0.000026 \mathrm{~m}$ the process reached an equilibrium before the cells died, but beyond these concentrations they died before the equilibrium was reached.

As shown in Fig. 9, the equilibria reached are about 1.45 times greater in $\frac{M}{750}$ than in $\frac{M}{150}$ buffer solution at all of the given concentrations of outside dye solution. This indicates that the dilution of the buffer solution affects the accumulation of the dye in the cell in the same manner at all concentrations of the external dye solutions when the $\mathrm{pH}$ value remains unchanged. This effect is in all probability due to the rise in the $\mathrm{pH}$ value produced by the dilution rather than to the difference in the concentration of the salts in the buffer solutions. If the concentration of the buffer is $\frac{M}{150}$ and remains unchanged while the $\mathrm{pH}$ value is raised by the same amount as would occur if it were diluted to $\frac{M}{750}$ there we find approximately the same increase in the concentration of dye in the sap at equilibrium in both cases. The results certainly show that raising the concentration of $\mathrm{Na}_{9} \mathrm{HPO}_{4}$ does not increase the accumulation of the dye in the sap.

VII.

\section{The Effect of Temperature.}

In order to make the analysis complete it is necessary to determine the effect of the temperature on the process of accumulation.

For this purpose the rate of accumulation at $20^{\circ} \mathrm{C}$. was measured with $0.00001 \mathrm{M}, 0.00002 \mathrm{M}, 0.00004 \mathrm{M}$, and $0.00008 \mathrm{M}$ dye solutions (Grübler) at $\mathrm{pH} 6.9 \frac{\mathrm{M}}{150}$ phosphate buffers to compare with the results at $25^{\circ} \mathrm{C}$. (Table I). The result is shown in Figs. 10,11, and 12.

The velocity constants were calculated as before (Section IV) by using the equation for an irreversible unimolecular reaction.

The average velocity constant of accumulation for $0.00001 \mathrm{M}$ outside dye concentration at $20^{\circ} \mathrm{C}$. is 0.0064 , while at $25^{\circ} \mathrm{C}$. it is 0.0155 . 
From this we may calculate $Q_{10}$ from the equation, ${ }^{23} Q_{10}=\left(\frac{k_{1}}{k_{2}}\right)^{\frac{10}{t_{1}-t_{2}}}$ in which $k_{1}=$ the velocity constant at $25^{\circ} \mathrm{C} .\left(t_{1}\right)$ and $k_{2}=$ the velocity constant at $20^{\circ} \mathrm{C}\left(t_{2}\right)$.

From this we obtain the value ${ }^{24} Q_{10}=5.9$. In the same way we may find $Q_{10}=4.4$ for $0.00002 \mathrm{M}$ when $k_{1}=0.016$ and $k_{2}=0.0076$.

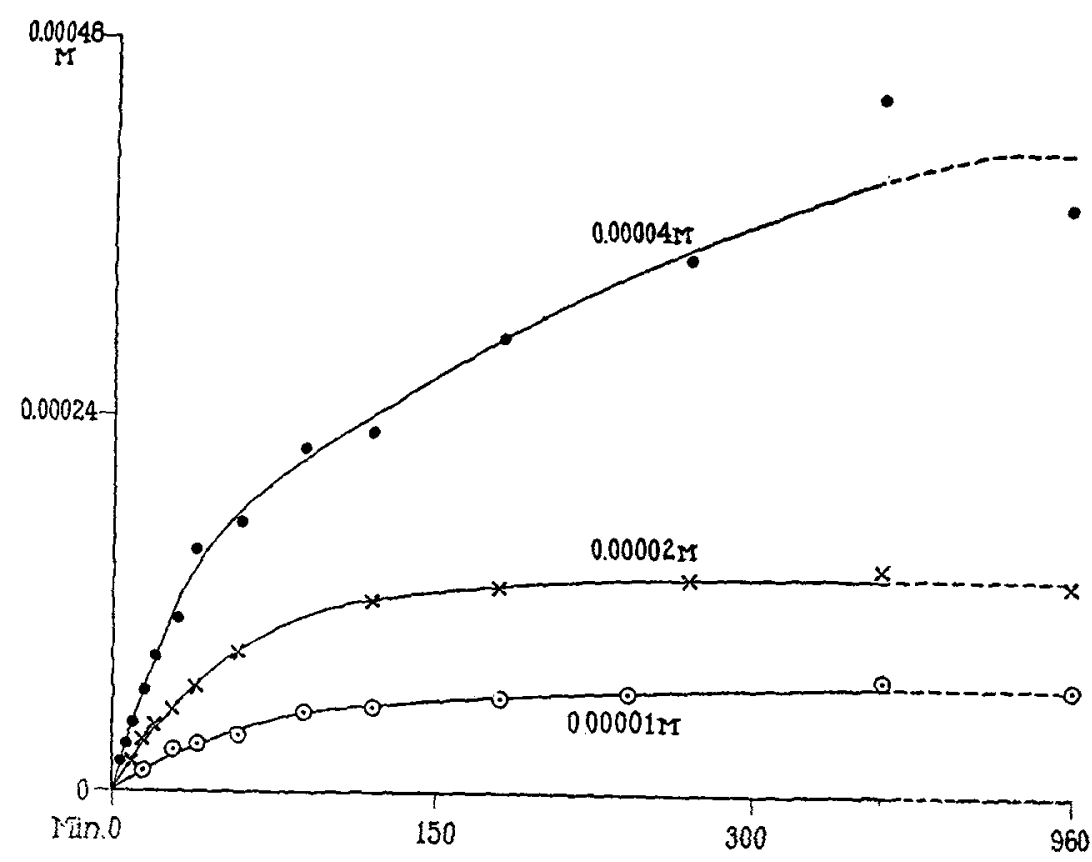

FIG. 10. Curves showing the accumulation of cresyl blue (Grübler) in the vacuole of living cells of Nitella in different concentrations of outside dye solutions at $\mathrm{pH} 6.9\left(20^{\circ} \mathrm{C}\right.$.), when equilibrium is reached. Abscissæe represent time and ordinates the concentrations of dye in the sap.

${ }^{23}$ Kanitz, A., Temperatur und Lebensvorgänge, Berlin, 1915, 13.

${ }^{24}$ The effect of temperature on the velocity of reaction was also calculated by the formula of Arrhenius.

$$
K_{1}=K_{0} e^{\frac{\mu}{2}\left(\frac{T_{1}-T_{0}}{T_{1} T_{0}}\right)}
$$

where $T_{1}$ and $T_{0}$ are two absolute temperatures, $K_{0}$ is the velocity of reaction at $T_{0}$, and $K_{1}$ is the velocity of reaction at $T_{1}$, and $\mu$ is a constant. $\mu$ for the experiments described in this paper is as follows: 
For $0.00004 \mathrm{M}$ the average velocity constants cannot be used, since they decrease steadily at $20^{\circ} \mathrm{C}$. and at $25^{\circ} \mathrm{C}$. Therefore the rate (the reciprocal of the time required to reach a given concentration in the sap) was taken at an early stage of the reaction, and the value $Q_{10}$ (average of 3 for $0.000017 \mathrm{M}, 0.000026 \mathrm{M}$, and $0.000035 \mathrm{M}$ dye in sap) was found for $0.00004 \mathrm{M}$ outside dye concentration.

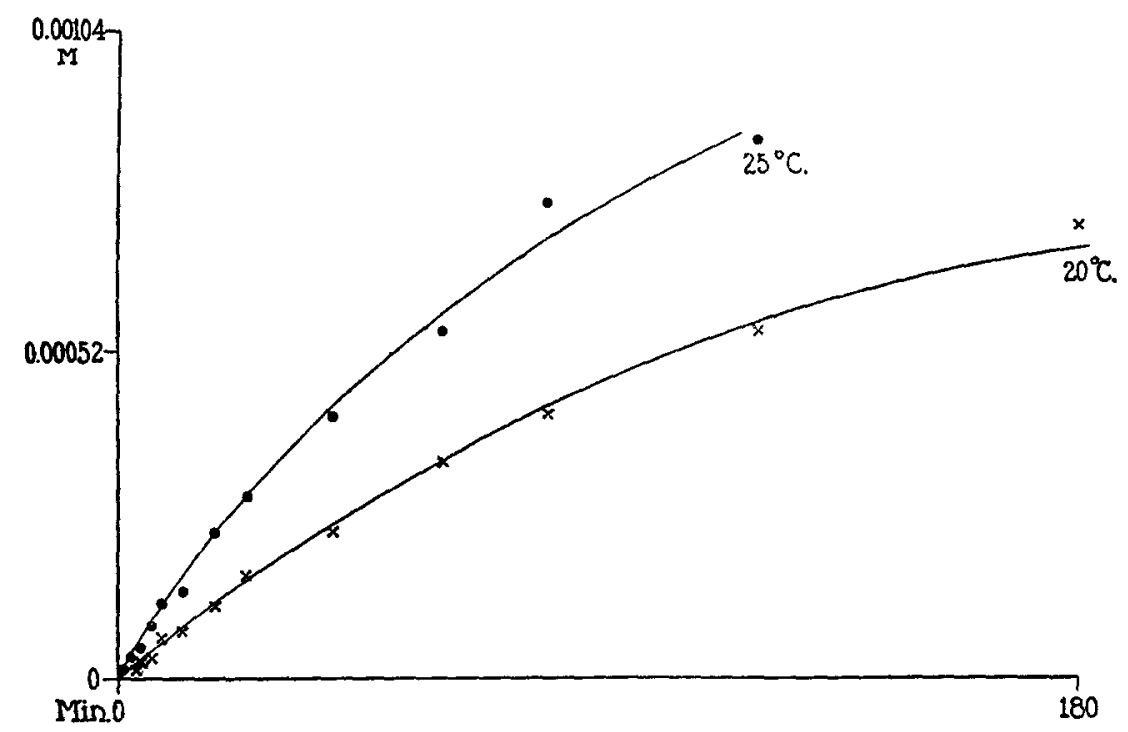

FIG. 11. Curves showing the accumulation of cresyl blue (Grübler) in the vacuole of living cells of Nitella in $0.000081 \mathrm{M}$ outside dye solution at $\mathrm{pH} 6.9$ (at $20^{\circ}$ and $25^{\circ} \mathrm{C}$.). Abscissæ represent time and ordinates the concentrations of dye in the sap.

Thus, if the rate proportional to $k_{1}=38.46$ and the rate proportional to $k_{2}=18.18$, we get the value $Q_{10}=4.5$; the average $Q_{10}$ $=4.6$.

For $0.00001 \mathrm{M}$ outside dye solution, $\mu=30,892$; for $0.00002 \mathrm{M}, \mu=25,993$; for $0.00004 \mathrm{M}, \mu=26,174$. Since this equation is significant only for an irreversible reaction, the values of $\mu$ obtained in the case of the writer's experiments, which represent reversible reactions may be used only for comparison. $C f$. Arrhenius, S., Quantitative laws in biological chemistry, London, 1915, 49. Crozier, W. J., $J$. Gen. Physiol., 1924-25, vii, 123. 
With the outside dye concentration of $0.00008 \mathrm{M}$ (Figs. 11 and 12), when no equilibrium can be reached before the death of the cells takes place, $Q_{10}$ was calculated as it was done for $0.00004 \mathrm{M}$.

When the average of $Q_{10}$ is taken from five points on the curve at the beginning of the reaction when the dye in the sap is less than the dye in the outside dye solution, $0.000017 \mathrm{~m}-0.00006 \mathrm{~m}$, it is found to be 4.8. When the average of $Q_{10}$ is also taken from five points on the

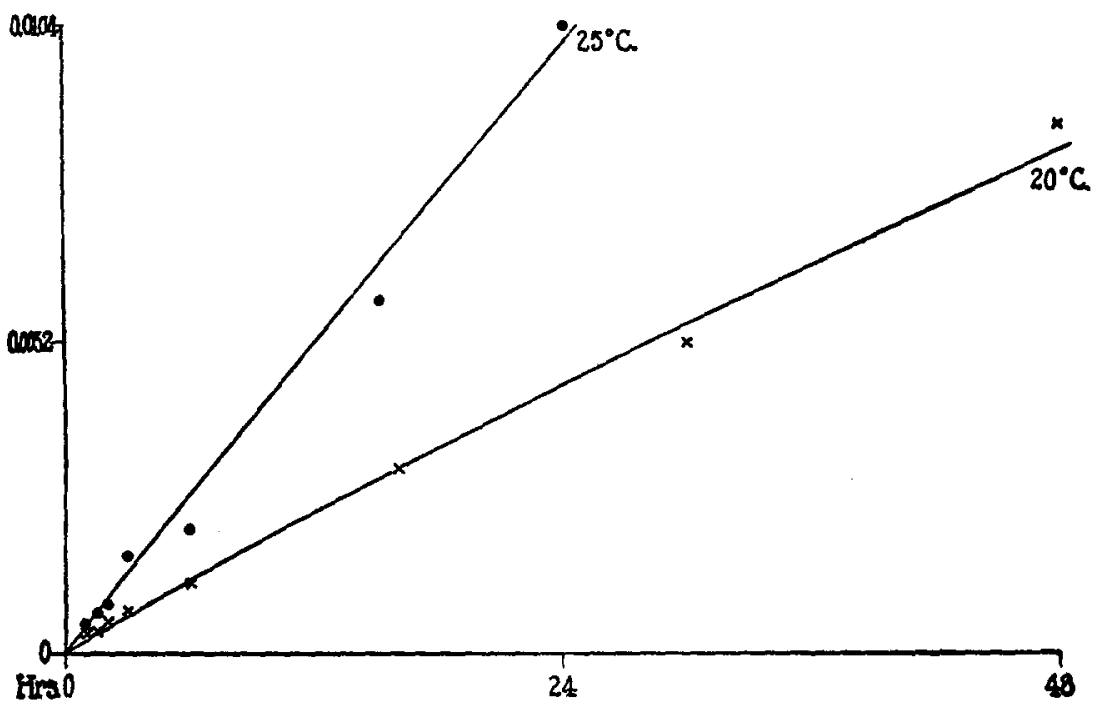

Fig. 12. Curves showing the accumulation of cresyl blue (Grübler) in the vacuole of living cells of Nitella in $0.000081 \mathrm{~m}$ outside dye solution at $\mathrm{pH} 6.9$ at $20^{\circ}$ and $25^{\circ} \mathrm{C}$. Abscissæ represent time and ordinates the concentrations of dye in the sap.

curve later on when the dye in the sap is accumulating, 20.00035$0.002 \mathrm{M}$, it is found to be 4.7. Thus it appears that the master reaction is a chemical ${ }^{25}$ one from the very beginning of the reaction where the dye has not yet begun to accumulate in the sap.

${ }^{25}$ The high temperature coefficient might be thought to be due to the rate of sap movement and not to the rate of combining of dye with the cell substance, but the following facts indicate that this explanation is incorrect. The temperature coefficient of the sap movement of Nitella which stirs the dye in the sap for $15-26^{\circ} \mathrm{C}$. is about 2 (cf. Kanitz, A., 1915, Temperatur und 
It is a striking fact that there is no perceptible shift of equilibrium with increase of temperature from $20^{\circ} \mathrm{C}$. to $25^{\circ} \mathrm{C}$.

VIII.

Theoretical Discussion.

Theories concerning the staining of living cells are numerous. ${ }^{26}$

It has been considered by some that the staining of cells is due to adsorption ${ }^{27}$ rather than to chemical combination. In the case of Nitella (even if we suppose that there are dispersed particles in the sap capable of adsorbing the dye so as to give the appearance of a true solution of dye), the accumulation of the dye in the cell vacuole does not seem to be explainable on the basis of adsorption for several reasons; one is that the temperature coefficient is about 4.9 which disagrees with that generally obtained for adsorption; another is (as already stated) ${ }^{20}$ that the slope of the straight line obtained by plotting $\log$ concentration of the dye in the vacuole against the log concentration of the dye in the external solution at equilibrium is $45^{\circ}$ which is not what would be expected for adsorption. The situation is complicated by the presence of non-colloidal substances in the cell (e.g., organic acids) which are capable of combin ingwith the dye and would compete for it.

- Previous authors have apparently not mentioned Donnan equilibrium in this connection but it is desirable to consider it because it is probable that every living cell contains non-diffusible ions. As

Lebensvorgänge, Berlin, 1915, 87, 88) so that the rate of stirring is doubled for a rise of $10^{\circ} \mathrm{C}$, in the region of $20^{\circ}$ and $25^{\circ} \mathrm{C}$. (the temperatures used in the writer's experiments). The value of the velocity constant of diffusion is found to be proportional to the two-thirds power of the rate of stirring ( $c f$. Taylor, H. S., A treatise on physical chemistry, New York, 1924, ii, 945), so that if the rate of accumulation of the dye were dependent on the protoplasmic movement, the temperature coefficient for accumulation would be less than 2 , but the experimental results show that it is about 4.9.

${ }^{26}$ For reviews on theories of accumulation of dye, $c f$. Bayliss, W. M., Principles of general physiology, New York, London, Bombay, Calcutta, and Madras, 1915. Höber, M. R., Physikalische Chemie der Zelle und der Gewebe, Leipsic and Berlin, 1914. Stiles, W., Permeability, London, 1924.

${ }^{27}$ Redfern, G. M., Ann. Bot., 1922, xxvi, 511. Bayliss. ${ }^{26}$ 
already stated ${ }^{20}$ it is difficult to make definite assumptions since the nature and concentration of the ions (diffusible and non-diffusible) are not well understood. The presence of two semipermeable membranes (one at the outer surface and one surrounding the vacuole) is a complication. The fact that ions do not appear to pass readily through these surfaces would be an objection to applying Donnan's conception $^{28}$ but if we use that of Procter and Wilson ${ }^{29}$ the difficulty disappears. Procter and Wilson base their conception on the law of mass action (which appears to hold, although as Donnan states we know that this cannot really be the case): if we adopt this as empirically true in this instance we may say that if undissociated molecules can pass through the membrane and dissociate on both sides it comes to the same thing as if the ions themselves could penetrate the membrane.

The best test for the Donnan equilibrium would be a comparison of the ratio of $\stackrel{+}{D}$ ions inside and outside, with the ratio of other diffusible ions, but this is not possible at present.

Fuller discussion will be reserved for the future, though it may be worth while to note here that the ratio between the concentration of the dye in the sap and that of the outside medium ${ }^{20}$ was found to be constant for the range of concentrations between $0.000005 \mathrm{M}$ to $0.00002 \mathrm{M}$ external dye solutions as would be expected on the basis of the Donnan equilibrium if the conditions such as $\mathrm{H}$ ion concentrations in the cell sap and in the external dye solutions remain unchanged, in the case of the experiments described in the present paper.

Let us now consider two explanations which lead up to the ones adopted by the writer as most nearly in accord with the facts, at least at the present moment.

An explanation ${ }^{30}$ involving the combining of the dye with the pro-

${ }^{28}$ Donnan, F. G., Chem. Rev., 1924, i, 73.

${ }^{29}$ Procter, H. R., and Wilson, J. A., J. Chem. Soc., 1916, cix, 309. Loeb, J., Proteins and the theory of colloidal behavior, New York and London, 1922, 130.

${ }^{30}$ Bethe, A., Biochem. Z., 1922, cxxvii, 18. Rohde, K., Arch. ges. Physiol., 1920, clxxxii, 114. Pohle, E., Deutsch. med. Woch., 1921, xlvii, 1464. Collander, R., Jarhb. wissensch. Bol., 1921, lx, 354. Mathews, A., Am. J. Physiol., 1898, i, 445. 
tein in the cell has been given by many investigators, who believe that on the alkaline side of the isoelectric point the protein takes up the basic dye, while on the acid side it takes up the acid dye.

Another explanation ${ }^{31}$ has been made by some on the assumption that the undissociated $\mathrm{DOH}$ (the dye hydrate) enters the cell and that the dye salt and $\stackrel{+}{D}$ ions cannot enter. They suggest that the accumulation of a basic dye in the vacuole is due to the combining of the DOH with the acid in the sap so that the dye could not come out of the vacuole.

Heretofore it has not been possible to explain with certainty the mechanism of accumulation of the dye by means of the last two theories either on account of uncertainty as to the condition of the cells used (whether uninjured or not), or on account of the lack of sufficient quantitative determinations for thorough analysis.

Though the experiments described in this paper alone are insuffcient for definite conclusions regarding the mechanism of accumulation of the dye in the cell sap, the analysis of the data obtained on the basis of quantitative experiments makes it possible to approach nearer toward a correct explanation than before.

In the present paper the experiments show that the higher the concentration of external dye solution the higher is the concentration of the dye in the sap at equilibrium, and that this process may be regarded as a reversible pseudounimolecular reaction. Since from the experiments it is not possible to show in what part of the cell this controlling reaction takes place the following suggestions are made.

Let us first suppose that the controlling reaction takes place in the surface layer of the protoplasm as was partly suggested by the writer in a previous paper. ${ }^{6}$ We may assume that the substances combining with the dye increase as the $\mathrm{pH}$ value increases and that the dye combines with weak acids, proteins, or their salts XA, at the surface according to the equation:

$$
\mathrm{DS}+\mathrm{XA}=\mathrm{DA}+\mathrm{XS}
$$

If we assume that XS may be eliminated from the equation on

s1 Overton, E., Jahrb. wissensch. Bot., 1900, xliii, 669. Harvey, E. N., J. Exp. Zool., 1911, x, 507. Robertson, T. B., J.Biol. Chem., 1908, iv, 1. McCutcheon, M., and Lucke, B., J. Gen. Physiol., 1923-24, vi, 501. 
account of the excess of XS already present in the surface layer and if $\mathrm{DA}$ is slightly dissociated or slightly soluble, then, at equilibrium the reaction may be represented by the equation:

$$
\frac{(\mathrm{DS})_{e}(\mathrm{XA})_{e}}{(\mathrm{DA})_{e}}=K
$$

in which the subscript $e$ denotes concentrations at equilibrium.

If we assume that $\mathrm{XA}$ is an amphoteric electrolyte which forms negative $\bar{A}$ ions when the $\mathrm{pH}$ of the cell is above 5 or a weak acid (with ionization suppressed at $\mathrm{pH}$ 5) then the higher the $\mathrm{pH}$ value of the cell, the greater is the number of $\bar{A}$ ions capable of combining with the dye.

When DA is formed, it can enter the vacuole but it cannot come out of the cell. As DA leaves the surface layer to enter the vacuole, more is formed in the surface layer. This continues until the concentration of DA in the protoplasm and vacuole is equal to the concentration of DA in the outer surface, which is in equilibrium with the concentration of DY in the external dye solution.

Thus the concentration of $\mathrm{DA}$ at equilibrium in the sap and the rate of accumulation of DA in the sap are dependent on the concentration of $\bar{A}$ ions in the surface layer of the protoplasm and on that of the dye. The same principle can be applied to the coming out of the dye from the cells. The process of accumulation is reversible and the dye will come out of the cell sap if the cells are placed in solutions without the dye. Since the concentration of $\bar{A}$ ions decreases with decrease in the $\mathrm{pH}$ value of the cell surface the $\stackrel{+}{\mathrm{D}}$ ions already in combination with A ions will be freed and we should expect the $\stackrel{+}{D}$ ions to come out of the cell when the $\mathrm{pH}$ is lowered, as we find in the case of stained cells placed in buffer solutions at different $\mathrm{pH}$ values.

Since the above theory requires the presence of $\stackrel{+}{\mathrm{D}}$ ions in the external dye solution, the question is raised as to how tenable it is when the writer's experiments on the partition of the dye between chloroform and water show that a considerable decrease in $\stackrel{+}{\mathrm{D}}$ ions takes place with an increase in the $\mathrm{pH}$ value of the dye solution until at $\mathrm{pH} 9$, 
where the accumulation of the dye in the sap is the greatest, there are practically no $\stackrel{+}{D}$ ions present in the external dye solution. Unless we assume, therefore, that the increase in $\bar{A}$ ions takes place much more rapidly than the decrease in $\stackrel{+}{\mathrm{D}}$ ions, it would not be possible to use the above theory to explain the mechanism of accumulation of the dye.

If we try to explain accumulation on the basis of adsorption by saying that $\mathrm{DOH}$ is adsorbed by the colloidal particles in the surface layer, it would be difficult to explain how such particles would migrate into the vacuole.

Loeb has found that a basic dye such as neutral red is taken up by a gelatin on the alkaline side of the isoelectric point, to form a dissociated compound while it cannot be taken up by the same dye on the acid side. The writer has made rough experiments on the accumuulation of brilliant cresyl blue by the gelatin at different $\mathrm{pH}$ values, and found that the higher the $\mathrm{pH}$ values, the greater was the accumulation of the dye, but it is difficult to state here whether the mechanism of accumulation in this case can be satisfactorily compared with that of the accumulation in Nitella.

There is another way of looking at the combination between the dye and the constituents of the cell. Since the dye accumulates in the sap, it might be natural to suppose that the reaction takes place in the sap. Since a progressive increase in the concentration of $\mathrm{DOH}$ in the dye solution is known from the writer's experiments to take place with increase in the $\mathrm{pH}$ value of the dye solution, and since the concentration of dye in the sap at equilibrium increases with increase ${ }^{32}$

${ }^{32}$ It is difficult to discover what would happen if the $\mathrm{pH}$ of the external dye solution remained constant while the $\mathrm{pH}$ of the sap changed, because as soon as the $\mathrm{pH}$ value of the sap is altered (for example, from $\mathrm{pH} 5.6$ to $\mathrm{pH} 6$ ) the injury to the cells is made evident by the disarrangement of chlorophyll (Hoagland and Davis state that the chlorides come out of the sap when pH of the sap is changed by the entrance of $\mathrm{NH}_{4} \mathrm{OH}$ and from this they conclude that the cells are injured). Since an increase in the $\mathrm{pH}$ value of the cell sap of living Nitella resulting from the entrance of $\mathrm{NH}_{4} \mathrm{OH}$, is associated with a decrease in the rate of accumulation of brilliant cresyl blue in the sap, McCutcheon and Lucke concluded that the increase in the $\mathrm{pH}$ value of the cell sap caused a decrease in the rate of accumulation of the dye. But from their experiments it is difficult to tell whether this decrease in the rate is due to the presence of $\mathrm{NH}_{3}$ in the sap or in the external 
in the $\mathrm{pH}$ value of the external dye solution (though the $\mathrm{pH}$ value of the sap remains unchanged when a normal cell is placed in a solution of the same $\mathrm{pH}$ value without the dye) it may be assumed that it is the undissociated DOH molecule alone that enters the cell vacuole while $\stackrel{+}{\mathrm{D}}$ ions and dye salt cannot penetrate the surface layer of the cell. At equilibrium the concentration of $\mathrm{DOH}$ in the sap is equal to that of $\mathrm{DOH}$ in the outside dye solution, and the concentration of the salt DA formed according to the equation:

$$
\mathrm{DOH}+\mathrm{XA}=\mathrm{DA}+\mathrm{XOH}
$$

(in which XA represents substances in the sap, either weak acids, proteins, or their salts) is dependent on the concentration of DOH and of XA in the sap.

The diffusion is assumed to take place more rapidly than the reaction between $\mathrm{DOH}$ and $\mathrm{XA}$, so that the rate is dependent on the latter, which accords with the fact that the temperature coefficient is about 4.9 .

In the sap is found a mixture of salts and acids. There is a considerable amount of potassium and halides, and there may be a mixture of organic substances such as malic, carbonic, tartaric, tannic, and citric, and amino acids and proteins. This mixture of various sub-

solution which may compete with the dye or due to the actual increase in the $\mathrm{pH}$ value of the cell sap. The writer tried to do experiments in which the rate of accumulation of the dye in the sap was measured when the $\mathrm{pH}$ of the sap remained constant, while the concentration of $\mathrm{NH}_{3}$ in the sap varied. This experiment would be possible if we could prevent the cells from becoming injured, because the $\mathrm{pH}$ of the sap rises to a certain maximum as the $\mathrm{NH}_{3}$ enters, after which it remains practically constant, while $\mathrm{NH}_{3}$ continues to accumulate. But unfortunately cells do not remain uninjured for any length of time after the $\mathrm{pH}$ value of the sap has changed to this extent, so that the writer is unable to show at present why the decrease in the rate of accumulation of the dye in the sap takes place when $\mathrm{NH}_{8}$ accumulates in the cell sap, but the investigation is being continued so that in the future it may be explained. So far as the entrance of $\mathrm{CO}_{2}$ is concerned, the writer finds that the $\mathrm{pH}$ value of the sap remains unchanged when the living cells of Nitella are placed in distilled water through which $\mathrm{CO}_{2}$ was passed until the $\mathrm{pH}$ of the water turned from $\mathrm{pH} 6$ to $\mathrm{pH} 5.2$ at $23^{\circ} \mathrm{C}$. In this case the cells die in about 1 hour so that the experimental conditions are rather unsatisfactory. Experiments are being made in order to settle the question. 
stances makes calculation difficult, since the quantity as well as the nature of these substances is not yet known. But if we treat them collectively and represent them by XA which combines with DOH we get the theoretical values of $\mathrm{DA}$ in the sap agreeing with the observed, when the values of DA at equilibrium are calculated by the equation:

$$
\frac{(\mathrm{DOH})_{e}(\mathrm{XA})_{\mathrm{e}}}{(\mathrm{DA})_{e}}=K
$$

and where the observed values of DA are obtained from $\frac{(d x)}{(d t)}$ as already explained.

It is of interest to add here that DOH may combine with $\mathrm{XA}$ just as a hydrate of a heavy metal such as copper will unite with a salt of tartaric acid to form a compound ${ }^{33}$

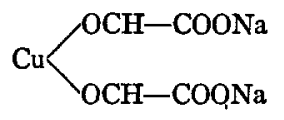

$+$

We may also suppose that $\stackrel{+}{\mathrm{D}}$ unites with protein as in the experiments of Northrop. ${ }^{34}$

So far as the mechanism of accumulation is concerned, this assumption $^{35}$ fits the facts and it is of importance to show further that it is applicable in the case of the coming out of the dye from the sap, as both processes must be explained by the same assumption.

In a previous paper ${ }^{6}$ it was stated that in the emergence of the dye from the cell the behavior of the dye was not in harmony with the supposition that the dye enters in the form of $\mathrm{DOH}$, but subsequent experiments with the absorption and giving out of the dye

${ }^{33}$ Norris, J. F., The principles of organic chemistry, New York, 1912, 272.

${ }^{34}$ Northrop, J. H., and Kunitz, M., J. Gen. Physiol., 1924-25, vii, 25.

${ }^{35}$ This theory might explain the experiments described by Harvey in staining living cells with a basic dye, where the vacuoles stained deeply and there was no staining of the cytoplasm. This difference in the capacity for staining between the vacuole and cytoplasm might be due to the fact that the $\mathrm{pH}$ of the cytoplasm is different from that of the vacuole (in which case the result would depend on the dissociation constant of $\mathrm{HA}$ ) or to a difference in concentration of XA or to the fact that in the vacuole XA represents substances different from those it represents in the cytoplasm. 
by chloroform have shown that this statement was not well founded. This may be made clear by a comparison of the cell with chloroform. In the case of the stained cells placed in buffer solutions containing no dye the dye comes out faster into a solution of low $\mathrm{pH}$, while the dye goes in faster in a solution of high $\mathrm{pH}$, though the $\mathrm{pH}$ value of the sap of a normal cell remains unchanged in buffer solutions (without the dye) at these $\mathrm{pH}$ values. At a high $\mathrm{pH}$ value, even if there is no visible $\mathrm{DOH}$ in the outside solution as $\mathrm{DOH}$ comes out of the cell there is bound to be a certain amount at the surface, which will tend to keep the DOH from coming out, and since the concentration of $\mathrm{DOH}$ in the sap is in equilibrium with that at the surface the reaction $\mathrm{DA}+\mathrm{XOH} \rightarrow \mathrm{DOH}+\mathrm{XA}$, in the sap, is hindered. This will make the dye come out of the sap more slowly. The opposite is the case with the stained cells placed in a solution of low $\mathrm{pH}$ value; there is a much smaller percentage of DOH present in an acid solution, so that there is less $\mathrm{DOH}$ at the surface of the cell, and consequently the reaction: $\mathrm{DA}+\mathrm{XOH} \rightarrow \mathrm{DOH}+\mathrm{XA}$ is not hindered.

An interesting analogy for this is found in the coming out of the dye from the chloroform into aqueous solution at different $\mathrm{pH}$ values. The affinity of DOH for chloroform is so great that unless there is a constant current of solution at high $\mathrm{pH}$ value washing the surface of the chloroform, DOH from the chloroform comes out slowly in an aqueous solution of high $\mathrm{pH}$ since there are $\mathrm{DOH}$ molecules at the surface which will hinder the coming out. On the other hand, when the aqueous solution is at low $\mathrm{pH}$ value, the percentage of DOH is low so that the coming out of the dye is aided. Here, too, just as in the case of the sap, the $\mathrm{pH}$ of the chloroform is not changed by the $\mathrm{pH}$ of the aqueous solution. It is therefore evident that the mechanism of the coming out of the dye is not in opposition to the assumption that the dye goes in as $\mathrm{DOH}$.

The hypothesis discussed last appears to be more probable, but the writer is at present unable to make a final decision. Further analysis of additional data is being made.

SUMMARY.

Living cells of Nitella were placed in different concentrations of brilliant cresyl blue solutions at $\mathrm{pH}$ 6.9. It was found that the greater 
the concentration of the external dye solution, the greater was the speed of accumulation of the dye in the cell sap and higher was the concentration of dye found in the sap at equilibrium.

Analysis of the time curves showed that the process may be regarded as a reversible pseudounimolecular reaction.

When the concentration in the sap is plotted as ordinates and the concentration in the outside solution as abscissa the curve is convex toward the abscissæ. There is reason to believe that secondary changes involving injury take place as the dye accumulates and that if these changes did not occur the curve would be concave toward the abscissæ.

The process may be explained as a chemical combination of the dye with a constituent of the cell. This harmonizes with the fact that the temperature coefficient is high (about 4.9). Various other possible explanations are discussed. 